\title{
Entering the age of accelerated change: In search of equilibrium
}

\author{
Milan Zeleny* \\ Professor (Emer.) of Management Systems, Fordham University, New York, NY, USA
}

It is not difficult to observe that our world is rapidly getting out of kilter, slipping into disequilibrium, upheavals, uncertainty, human suffering and increasingly chaotic responses - thus weakening our grasp or even a vision of human, societal and individual future. Not everything can be attributed to COVID19 - which is rapidly changing from a cause to one of the symptoms of the increasingly unhinged world.

It is an ages-tested wisdom that, in order to solve any disease, failure or difficulty, one has to identify (and understand) its causes, not simply attack, mitigate or manipulate its symptoms. We usually can observe or identify symptoms or consequences, but often fail grasping the chain of primary causes. Symptoms can cause other phenomena, but each causal chain has also its primary cause. Hereby lays our main challenge: one has to be educated and skilled in logic and rational reasoning.

Yet, the people with the most power and skills of persuasion, ambition and emotion usually have no such training, experience or intelligence - especially the party politicians (not to mention those who vote for them). For these reasons we are evoking here, for the HSM journal, the institution of the strategic revival. ${ }^{1}$

\footnotetext{
${ }^{1}$ The Institution of Strategic Revival is necessary for all rotary journals, seeking evolutionary adaptation in a rapidly changing intellectual and scientific environment. Traditional journals are usually based on a closed, self-reinforcing loop of editors, authors, reviewers and a paradigm sustaining agents. After a while, even a successful journal becomes encapsulated within their protective membrane. Such journal is then effectively "behind", yet still safely on the prescribed lists of equally declining institutions. Keeping
}

We search for the new roads towards reliable entrepreneurship and management, allowing new generations to resist and defend against the choking grip of the divisive party politics.

For this purpose, we have selected addressing 7 phenomena:

1. Continued acceleration of the rate of change

2. Powerful tendencies from equilibrium to disequilibrium

3. Shifts from genetic to memetic forces of human evolution

4. Conflicts between state-interventionism and self-organized natural response

5. Misbalance between the rates of accepting the new and abandoning the old

6. Conflicts rising between the man-made and naturally self-sustainable worlds

7. Emerging needs for multidisciplinary education, thinking, research, and action

All of the above 7 phenomena will be dealt with throughout the text via specific applications, recommendations and examples. Only the first one (speed of change) is discussed separately now, at the beginning. It is the easiest to acknowledge and imagine, yet it is virtually ignored by science or philosophy, and its effects are fundamental and often devastating - especially if its causes are not properly understood.

up with the changes, HSM should continue as a self-renewing (autopoietic) and evolving entity, open to new paradigms, disruptive technologies, timely adaptations and trailblazing new authors from all over the world. 
Any self-renewing journal (like HSM) should avoid maintaining and protecting management systems which are already being surpassed by the change acceleration. Rather, journals should respond directly to the conditions and requirements of the changing reality. When new concepts are emerging faster, many old concepts have to be abandoned or discarded, at least equally fast. Naturally, only the self-sustainable or self-renewing systems should be preferred. The best publication is a timely and competent application.

Never learn from your own mistakes.

W. Edwards Deming

My old professor, W.E. Deming, often stressed that, in a rapidly changing society, we do not have the luxury of learning from our own mistakes. There is not enough time. There is also very little to gain by copying others. Learn from the mistakes of others! Find your own way! Politicians of mature economies, like the USA, Japan and Western Europe, have already made such a large number of mistakes, enough to last for generations. Learn from their own mistakes!

Why is the rate of change accelerating so rapidly? What are its main causes? And why can the consequences of speed acceleration be so devastating? Why are retrograde conservatism and its die-hards so ineffective? We have to consult natural evolution of human economic behavior and its evolutionary economics.

First, during the hunting-gathering phase of evolution, change was very stagnant and multigenerational: knowledge was safely transferred from parents to children, for millennia. The invention of agriculture was an economic breakthrough: people could stay in place, build infrastructure and organize common education. The concept of productivity growth emerged. Improving knowledge, tools and cooperation allowed increased production with a smaller number of people. Economic behavior emerged.

The next emerging sector was the industry: producing tools and machines, ultimately with the help of machines themselves. Productivity of agriculture accelerated and industrial production followed. As the industrialization progressed, its productivity increased and so the released workers had moved into a new sector of services. So, economic sectors are evolving in a productivity driven sequence of transformations: A->I->S. But the service sector has also experienced rapid productivity growth. The next employment sector is, by default, the government.
So, the transformation chain A->I->S->G is evolving faster, thanks to the faster productivity growth rate. That is why the developing countries are catching up, while the developed countries are slowing down or stagnating - at an increasing speed.

The problem is that there is no new economic sector! Humans can economically produce food (A), things (I) services (S) or nothing (G). The Government sector "lives" on its power of taxation of the classical sectors. The chain of transformations thus comes to halt, being increasingly robotized, automated and self-serviced. The economy tries to enter its metamorphosis (a profound change of form), but the G-sector fights back, maintaining its partybased power, fixating the status quo, trying to stop and often even reverse natural, productivity-based evolution.

Another powerful source of the speed of change comes from the growth of human-built environments. With the invention of agriculture, humans started building up permanent abodes, increasingly larger and more complex, leading to modern megacities and sprawling infrastructures. Direct contact and experience with the freely evolving nature has de facto disappeared. Adaptation to the natural environment has been replaced by cultural adjustments to built environments. People master complex environments and learn how to make them even more complex, round and round. Instead of the genetic evolution, human adaptations become more and more memetic (learned and copied). Necessary adaptations are less physical and behavioral, and more cultural. Human and natural environments become conflicting and increasingly incompatible. Cultural adaptation accelerates, while natural adaptation wanes. Humans and their natural environments enter into a seemingly insurmountable conflict.

\section{The G-sector}

The G-sector is consequently growing more powerful, more politically polarizing and increasingly more conservative, non-democratic and backward oriented. Instead of the evolutionary economics and searching for a better understanding of natural productivity acceleration, the G-sector (i.e. state, political parties, autocratic leaders) has assumed an unprecedented control and responsibility for the economy itself - manifested by rampant economic interventionism. 
So called "trumpism" has become a new paradigm for such interventionism: turning back and restoring the lost "greatness" - rather than embracing the opportunities of rapidly emerging futures. Economic evolution cannot be reversed; it can be slowed down or replaced by political interventions: who will produce what, sell to whom, and at what price or tariff, exported or imported - all determined by one person, party, or state. Such "trumpled" states are slipping backwards, while the future is offered to the free, bold, young and unafraid within the emerging economies. This is the group this HSM issue is attempting to encourage and stimulate. Extreme conservatism is quite suicidal in the era of accelerating change.

The waning "greatness" of the traditionally advanced economies is natural - they refuse to keep up with the speed of change. The real "greatness" can be found only in the future, never in the past. So, the solutions appear to be equally natural: enabling decentralization, re-localization of interests, self-government, free markets, entrepreneurship, cooperation, community enhancement, self-sustainability, etc. All are implied by the evolutionary tendencies: what is lacking, and needed now, is human understanding - not more of the hopelessly polarized social engineering. That is what we are endeavoring to encourage in the HSM.

\section{On the genesis of a Management System (the short story of the "Zeleny ZIPF")}

The era of accelerating speed of change requires a continuous evolution of new and reliable management systems - especially in journals like Human Systems Management. A lasting, self-renewing system must be original, adjustable and evolutionary. It cannot be copied; it must be invented at the source. It is not an easy process, but it can become one.

The story of ZIPF, originally called Revolver, or later Rotary, is very useful, even though grossly misunderstood and misapplied at its time. The process remains correct and self-sustaining even today (similar model was later evolved and successfully applied at Amazon.)

At the beginning there was Bata: "Our Customer, our Master!" (Customer is Zákazník in Czech: thus ZIPF and not CIPF.) Customer is the key: everything rotates and revolves around the customer satisfaction: always, everywhere and repeatedly. Repeatedly! That is the key, the axis and the center!
Later, at about 1994, at Fordham U. in New York, I overheard how colleagues and students laughed at some "bookseller" (Jeff Bezos) who tried selling books over the internet. I caught only: "He has no profits!" What a laughable idea for a Stock Exchange! They roared. I remembered the: "no profits"! What a great idea! Reinvestment of profits! This guy understood business! Repeated satisfaction of customers! (Bezos understood money as a motor, as a revolver. He was not a bookseller, but a financial analyst: he just wanted to sell on the internet and he chose books as a simplest start-product. Plowing his profits back into satisfying his customers - this I understood.

I have already envisioned a windmill (I studied the Dutch culture at the time) and its blades: pushing them, one after another, until they started humming on their own, faster and faster! That was it! It just needed a steady energy.

At that time I also studied F. Porsche and his early electromobiles. His idea was simple: put the electricity generators directly into the wheels! As car moves, it also generates the electricity it needs to move. The faster it goes, the faster it can go. Any electricity deficits are handled by a simple self-charging storage battery. The process itself generates the energy needed.

That was it: the repeatability. How to get the company turning, over and over, on its own, so that the customer would be continually and increasingly better satisfied. I imagined the watermill at my Granma; and the windmills in Taiwan - turning and turning, generating and producing - all with a small storage battery, or a reserve pond in the watermill.

So, the customer $(\mathrm{Z})$ is the key, his satisfaction brings finances $(\mathrm{F})$ to be used for improving the process $(\mathrm{P})$ so that new and better satisfaction levels are generated. But the world is also changing and the rate of change accelerates: customer's needs are changing too, rapidly and continually: so we need adequate and continuing innovation (I). Thus, the ZIPF system of management is emerging: the 4 necessary and sufficient components: not more and not less: Customer (Z) ->Innovation->Processes->Finances.

The role of the CEO is to get the ZIPF rotation into equilibrium and balance, maintaining its growing productivity. That is what Jeff Bezos mastered: maintaining the ever changing dynamic equilibrium. Nobody else came close, it cannot be copied. It has to be "grown" in situ. So, Amazon just keeps rotating! Even COVID-19 has not stopped it, just the opposite. Nobody is laughing anymore. The others did not understand Bata-system and it's Our Customer, our 
Master! There could have been many more Amazons and many more Bata-towns - all over the world, cooperating, being as close as possible to their customers.

Even though we have tested ZIPF at several companies (in the CR), it has never worked. It is quite useful to know why. At about that time, the so called "Balanced Scorecard" (BSC) has also emerged. It was a simple accounting list of performance goals and indicators. Keeping the score was useful, simple, and quite naive. Among the indicators were also Z-F-PI plus a few others. But there was no management system! Whatever happens in a corporation brings forth the BSC of indicators. But BSC itself does not manage or bring any windmill to rotation. (One has to import a management system from the outside most likely ineffective.) That is why nobody uses BSC anymore, and only a few remember it. BSC was very simple and a number of indicators quite easy to expand; the then popular groups of CEO sycophants had good times with pushing the BSC. Gone with the wind!

It is quite obvious that using ZIPF properly will bring about a special culture of values, habits, preferences, behaviors and aspirations. People certainly think differently at and about Amazon.

The early version of ZIPF is presented in the sketch, as CIPF, in Fig. 1. Clearly, thinking iteratively, and acting in a revolving, upgrading and corrective fashion, should become the main part of the new entrepreneurial and corporate culture.

Responding to many customers fast, reliably and individually is not easy. When teaching AI (Artificial Intelligence) at Columbia U. in New York in the $80 \mathrm{~s}$ - using AI in ZIPF was my solution, but: AI then was too clumsy; I had to abandon the analog-based AI

\section{The self-reinforcing cycle of ZIPF}

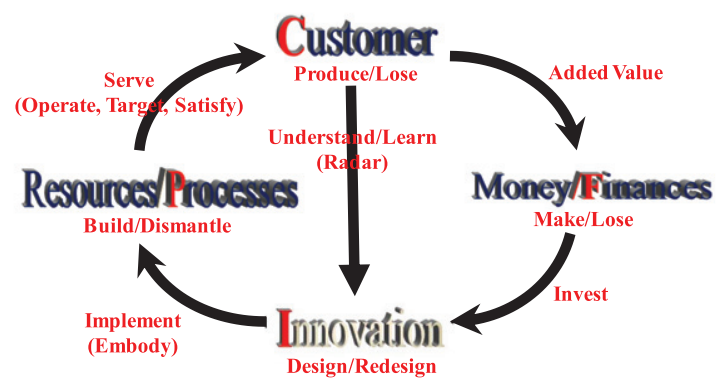

The Entrepreneurship is fundamentally iterative. So its management diagrams should be circular, revolving, or rotary

Fig. 1. The self-reinforcing cycle of ZIPF. research - there was no practical digitization available at that time. During my studies in Rochester, I had also worked at Kodak: I was aware of the first digital camera. But Kodak did not market it - and thus went bankrupt. Abandoning the analog AI saved my future carrier. Accepting the new requires abandoning the old. (Kodak did not abandon their instant photography. Similarly Enron, GE, Harley D., etc., all had ended by sticking too long with the too old.) A management system cannot be copied and inserted into ZIPF - it is itself a management system.

Of course, in a rapidly evolving environment, additional cultural traits should be acquired within a properly run ZIPF, or a similar rotary management system. For example, rapid change does not allow for a traditional strategy. Yet, you have to handle the future. Let us call it the Strategy of the first step. You take the first step, evaluate the impacts, and then take the next first step. It is like that every day is the Day 1 !

Only trumpism keeps repeating their obsolete triple: "winning - winning - winning". One does not just fight the competition, entrepreneurship is not rugby. One should not try to win and destroy, but rather engage, use, expand and cooperate - like they do at the Amazon.

\section{In search of equilibrium}

One of the key observations is that while the national economies are rapidly converging (See for example the fast advancement of China and even faster decline of the trumpled USA), the differences within countries - i.e. in terms of their component regional and local economies - are widening even faster. Yet, only the well balanced regional and local economies are the assurance of a well-balanced country or nation as a whole.

The mega-city concentration, of virtually everything and everywhere, indisputably forces most of our world out of balance and into disequilibrium. The centralized interventionism is the result, and local technology, education, self-government, selfsufficiency, resilience and independence are missing as the crucial components of a well balanced society.

Imagine: young entrepreneurs, managers, teachers, workers and farmers, being able to launch and maintain their carriers at the place they live (or even of their birth), maintaining full contact and communication with the world, avoiding wasteful and stressful daily commuting - similar to the experience of Bata, who built the town of Zlin and from their own town 
then reached and mastered the entire world - without a single politician ever interfering or even being in sight.

How do we reinstate the self-maintaining dynamic equilibrium and balance in all regions, advance local communities into knowledge-based relevance, creativity and originality, and thus restore the values of spontaneous and independent creation for the flowering of local economies as vital and cooperating human communities?

\section{Some examples from the ZET-Foundation projects}

Any country or nation should devote its efforts to achieving economic and social equilibrium of its components; i.e. of their regions, localities and communities, in terms of their economic independence, self-sufficiency, entrepreneurship and innovative originality. Such independence and selfdetermination lead to cooperation, coordination and local exchanges of specific knowledge, products and services - in the interest of the continued self-enhancement. Rather than the old-fashioned specialization and fractures, we have to search for transdisciplinary powers of Integrated Productive Environments (IPE).

When our world is out of kilter, then after failed globalization must follow a new re-localization. Any excessive centralization is counter-balanced by subsequent decentralization. Whenever political and social engineering ventures to overshoot, the nature forces them back into equilibrium. Restoration of balance - in economics, party politics, technology, and human relations - requires respecting the wisdom of nature, not the empty promises of professional interventionists.

Local self-organizing units are now capable of producing necessary and unique products and services with the highest possible added value, like the complex, integrated and maximum value-added production, agriculture and services integrated systems (similar to the Industrial cities of Bata) for export and exchange. This reconnects the world on the basis of local knowledge sharing, rather than on globalist political interventions and exploitations of tariffs wars. World trade and exchanges should be among the self-assertive, competent, independent and innovative local companies: not between the elected political and influential deal makers of retrograde thinking, acting on their doubtful promises and dreams of selfpreservation.
Among the ZET-projects are many additional topics, all of them closely related to the main concern of the section In Search of Equilibrium. Because of their importance, we offer selected characteristics below:

1. ZET-Town Network, coordinates the construction of complex, integrated production entities, often only partially completed, for export to economically challenged areas, as close as possible to the final customer, renewing autonomous communities - and thus alleviating forced migrations, external and internal while using the newest digital, modular, material and robotic technologies. At the same time we promote the electro-solar-wind complex of distributed and autonomous energy sourcing.

2. ZET-Tech-Share centers, support establishment of shared-technology centers, for the purpose of training and educating according to current enterprise needs in usage and improvement of modern technology. Our goal is the flourishing of local and regional autonomous economies and communities. Consortium of companies thus affords a study and use of the latest and most expensive technologies to increase cooperation and competitiveness of companies and institutions in the ZET-network.

3. ZET-cubator Startups develop education and training of the entrepreneurial talent through the Entrepreneurial universities and innovation centers. Both innovation "cubators" and startups, also with foreign participation, not only renew and strengthen the legacy of the Batasystem, but also raise it to the levels of current and modern problems, contexts, technology and knowledge.

4. ZET-camps represent opportunities for the young, often disadvantaged or handicapped youth, directed towards awakening their talents, encouraging the zest for life, and promote goal-directed, ethical and creative habits and skills during the earliest times of the formation of character, abilities and goals of the young people. We emphasize entrepreneurship, cooperation, and search for one's own road to success.

5. Entrepreneurial ZET-Impulse: specific local entrepreneurship corridor (Ostrava-ZlinBrno-Breclav-Bratislava), conceived as a network of cooperating entrepreneurial universities, open to local as well as foreign talent, distinguished by specific and original 
tasks - like new companies creation, integrated productive towns and unique startups - renewing the traditions, heritage and abilities of the best within us, in the world around us - as it is required by our times, the new contexts and unprecedented era of change.

6. ZET-authority, allowing for the possibilities of de facto self-accreditation in the areas of entrepreneurial education for both state and private universities. The cooperation of these institutions is critical for the early establishment of innovative, entrepreneurial and strategic habits. Small and medium enterprises are the foundation for developing new, re-localized economies. Freedom and autonomy of such private initiatives and institutions should be preserved.

7. Entrepreneurial University comes from the vision of Jan A. Bata (genius Czech entrepreneur), seeking massive preparation of highquality, professionally, and ethically anchored entrepreneurs, capable of creating jobs, realize needed innovations and strengthen local economies and communities. Entrepreneurship cannot be learned by reading books on entrepreneurship. Entrepreneurs learn by action: founding companies, analyzing markets, creating teams and mastering technologies. Entrepreneurship is knowledge (action), not information (description of action). There is a plenty of information and critical shortage of knowledge. Information is not knowledge.

8. ZET-solutions address the problem of growing number and intensity of conflicts, in the world society and business, while noting the decline in human abilities to solve them. Traditional solutions do not remove conflicts, but rather bring forth the new ones. Emerging ,trumpism” attacks problems through the direct confrontation of opposing sides, in search of some compromise or consensus. In contrast to such "compromise"- which is harming both sides, ZET offers the "conflict dissolution" (instead of the traditional resolution), through seeking or creating the prominent alternative, assuring for both sides better solution than the traditional compromise.

9. Self-Renewing ZET-Corporation. In the era of accelerated change, both survival and legacy of traditionally organized corporations are increasingly at risk. The ZET-Corporation cannot function as one, unitary and singly organized complex enterprise. Modern enterprise must function as a triune sliding organization of sections of the past (leaving), present (being) and future (becoming). Essentially, the goal is to secure the process of continuous and accelerating innovation. Individual organizational sections must be sufficiently autonomous in order to adapt to different contexts of their entrepreneurial function.

10. ZET -university. In the era of Change Acceleration, self-taught courses and self-studies will become indispensable accompaniments to traditional school and university education. Instead of passive lectures, instead of simple information, the emphasis will shift to knowledge. Knowing implies being able to do something. Concrete assignments of yet unsolved problems will prevail and be approached through problem-solving teams.

\section{Evolutionary economics}

The acceleration of change is evolutionary, substantial and lasting. The traditional notion of status $q u o$, and any attempts for conservation or turning back have become unsustainable, approaching virtual insignificance. There is, naturally, even faster aging and demise of ideas, approaches, knowledge, understanding and values, not only between generations, but increasingly so within the same generation.

We have considered the following evolutionary chain of transformations in human economic activity and prevailing employment: Hunting \& gathering $\rightarrow 1$. Agriculture $\rightarrow 2$. Industry $\rightarrow 3$. Services $\rightarrow 4$. State $\rightarrow$ ? What comes next? In the following diagram we explore so called Local Entrepreneurial Environments. (The pre-agriculture, was not economically interesting.) Only with the invention of agriculture, the first truly economic sector emerged. After agriculture followed industry, then services, and after services the state (as a way of employment): the four basic sectors altogether. Because there can't be a fifth sector, after a series of four transformations, there can be no "Fifth transformation". There can only follow a metamorphosis. Humans can, economically, only produce food, make things (tools, machines, products), provide services - and maintain state (employment based on the collection of taxes). Because of the productivity growth, the employment in individual sectors tends to be declining. This is outlined in Fig. 2. 


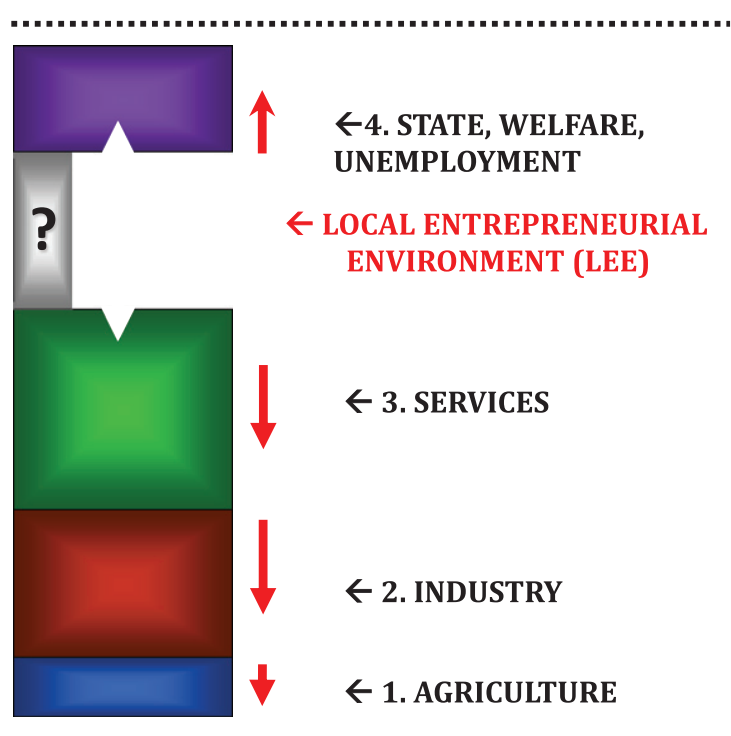

Fig. 2. Metamorphosis towards Local Entrepreneurial Environments (LEE) (the arrows indicate long-term tendencies to employment decline.

\section{On the role of productivity growth}

Each sector transformation is accompanied by a move from the lower to higher productivity activities and, correspondingly, by the accelerating loss of employment in the waning sector and a shift of jobs into the waxing sector. The main condition for any transformation is the productivity acceleration (less and less people needed for producing the same or sustainable levels of production), or a new and potentially more productive technology of production. (Many so called "low-unemployment" economies are suffering from declining productivity - thus being bound to stagnate in the old types of technology and retrograde old-industrial doldrums.)

For example, in food production: although the hunting and gathering was steadily improving its productivity, the invention of agriculture became even a more productive option: the productivity accelerated and redundant people could move to the new sector of industrial production of things. It is the high productivity of agriculture which leads to industrialization. Agricultural revolution thus spawns the Industrial revolution. That is how all transformations are related. (Why is, for example, Somalia stuck in agriculture and "starving"? Because the lowproductivity agriculture employs most of the workforce-low unemployment - and the move to the next sector, or the new technology, is thus prevented.
Jobs have always been disappearing from highproductivity waning sectors and transferred into lower-productivity waxing sectors. Of course, people losing their jobs tried to protect them, sabotaged machines, revolted, fought, etc. Upheavals, revolutions and wars always accompanied transformations. Yet, there were never any reversals. Natural laws of evolution remain irreversible. (Of course, stasis, stagnation and politically imposed self-conservation were and are often disrupting natural evolutionary processes.)

It is quite remarkable that humans never learned from their experience, always trying to reverse, stop or slow down these inevitable transformations - even more today, in the 21.Century. In the USA, the followers of Trump are still fighting to retain traditional jobs in coal mines, oil fields, steel factories, traditional farming, etc., through a variety of forms of political tribalism, promises and votes-seeking demagoguery. What is even more remarkable: not only manual workers and political followers are trying to reverse evolutionary gains of productivity growth, but also some intelligentsia, waning entrepreneurs and traditional schools - even some economists - are still trying slowing down or reversing the history.

(How could we reverse a traditional sector and its falling employment levels? Clearly, by limiting or even forbidding the use of new technology. That sounds almost idiotic, but recall how many politicians and "entrepreneurs" are recommending taxation of robots, automated factories, self-piloting cars and planes, etc. Such resistance to change is the major obstacle to avoiding stagnation, collapses, upheavals, terrorism and looming military conflicts.)

What is missing is a firmer grasp and understanding of the evolutionary laws, not only in natural systems, but increasingly in economic, social, educational, political and cultural systems. There lies the clear advantage and hope of so called developing economies, and the threat of secular stagnation, decline or even demise of some mature economies (like USA, Western Europe, Japan - and, increasingly, also China).

The evolutionary chain is spontaneously driven by the relentless productivity growth rate, accelerating enormously in the $21^{\text {st }}$ century. It has never been a matter of political choice. Individual transitions were accompanied by conflicts and wars, because of the lack of understanding and non-existence of Evolutionary economics. Productivity growth is a pre-condition for growing standards of living, and thus of peace. 
After the series of sector transformations, which were often confused with, or accompanied by, crises and recessions, the most mature economies (USA, Japan, and Western Europe) have reached the endpoint of the chain. Only food (1), things (2), services (3) and state (4) can be produced, manufactured, provided or paid for by human economic efforts. Yet, productivity growth must continue, to secure peace and prosperity. Thus the employment levels in all four sectors must continue declining, often at an accelerated regime. (In the USA, the rate of employment in the agriculture went from some $90 \%$ to $0.5 \%$ of the workforce, still falling rapidly.) The efforts of current populists and politicians to stop or reverse productivity effects of evolution are clearly useless, hopeless and dangerous. In our diagram (roughly the US situation), all four sectors are falling in their workforce share of employment.

Because the economy must go on and technology of productivity must grow, traditional sectors are bound losing employment, while people need ever more food, things and services. The state sector cannot maintain its employment levels: it is not a productive but a consumption sector, dependent on the taxation of the other three sectors. Its indebtedness and soaring inefficiency prevent its expansion, at least in highly developed economies.

These dynamics are fully captured in our diagram. Because the total workforce grows, and traditional employment levels fall in all sectors, there is only the space designated by "?" that is bound to keep expanding. This is where the economic metamorphosis enters and takes place.

A simple metaphor helps bringing this out. Imagine a caterpillar, living underground or feeding on leaves, adding segment after segment to its size. After a while, it cannot add new sectors, it cannot survive in its original environment. It nurtures itself within a pupa, changes its form, and emerges as a butterfly, capable of surviving, thriving and multiplying in the new environment. Metamorphosis is a relatively abrupt change of form, structure and substance - in our case of prevailing economic behavior and evolution.

Such metamorphosis is clearly visible in our diagram as the grey space "?", called LEE (Local Entrepreneurial Environments), is the rapidly expanding space of the new, re-localized, de-globalized and mass-entrepreneurial, digital economy, based on localized automation, robotics, AI and the high-added value of IPE (Integrated Productive Environments) of agriculture, industry, services, local self-government, education and social autonomy. In this new environment, the whole can only be as good as are its parts - not the other way around.

China today faces its historical opportunity of transforming into the "butterfly" stage of the evolutionary metamorphosis directly, with confidence, avoiding errors, detours and delays of the retrograde, populist "trumpism" - in all of its now varied forms and reincarnations.

\section{Explanation of failures}

Humans can understand only that they have themselves created, i.e. machines, mechanisms, political parties, armies, refugee camps, etc. They can't fully grasp what they have not designed: i.e. organisms, nature, economies - all spontaneous or autopoietic orders and systems in general. Such natural systems are falsely viewed as all kinds of machinery, thus pretending that organisms, economies and societies are of human design creations. This is the Great Fallacy and a source of current political, religious, environmental and economic failures.

All mechanistic systems can be (long-term) sustainable, especially if blessed with finances, resources, protection and subsidies from political support. Such "external maintenance" is only a poor substitute for the real, internal and organic self-sustainability. All important natural systems, including human societies and economies, must be, and are, self-sustainable (Unless interfered with by catastrophes or humans themselves).

A little baby is sustainable - through mother, machine or other support; but a redefined system: "mother+baby" is naturally self-sustainable and resilient in its environment. It is such system redefinition that is absent in current political discourse just missing the crucial point of much needed knowledge for survival, adaptation and resilience in out-of balance natural and human systems.

\section{Integrated productive environments}

Let us look more carefully at the metamorphosis space (grey region LEE) of our diagram (Fig. 1). We can readily understand its accelerating expansion, while all other sectors are contracting (in terms of employment), at least in mature, advanced economies. Less developed economies are still locked in one dominant sector (usually agriculture or industry), mainly because of the low productivity and consequently a nearly full employment, thus 
preventing much needed transformation to the next sector. Such economic doldrums are often induced by excessively conservative, status-quo devoted politicians.

The growing LEE region is typical of healthy economies, advancing towards metamorphosis. In spite of the declining employment in productivityaccelerating sectors, the production of food, things, services and political redistribution will continue to exist - but not in the traditionally separate sector forms.

The metamorphosis towards the LEE-space is characterized by a new process of integration. All traditional sectors productions are being combined into a coherent system of complementarities, cooperation, combination and even fusion. Traditional differences and distinctions are being progressively reduced. In other words, the LEE-space contains all four traditional "productions", combined into a large number of high added value options. The future of the ambitious and able entrepreneurship lies in Integrated Productive Environments (IPE).

The LEE metamorphosis is inevitable. The productivity growth rate criterion is rapidly changing into the maximization of added value criterion. The search for the highest added value already accelerates, traditional specialization is weakening. Economies are already being differentiated into the waning productivity-seeking ones, and the waxing addedvalue maximizing ones.

It is therefore necessary to reassess the separate, individual and specialized "productions" in terms of their mutual complementarity, entrepreneurial cooperation, share economy, and synergistic creation of innovative products and services - with maximum added value. Technology is quickly responding, undergoing a corresponding process of combination and recombination into integrated, multi-purpose modular complexes, abandoning the single-purpose, stand-alone components of the past.

It is difficult to identify one predominant leading technological breakthrough. Digitization has enabled successful revival of artificial intelligence (AI). Robotics, the Internet of Things (IoT), autonomous vehicles, 3-D printing, nanotechnology, biotechnology, materials science, autonomous energy storage, and accelerating quantum computing - to list just a few. All of them promise to significantly redefine traditional agriculture, manufacturing and services, thus blurring the lines between physical, digital, and biological spheres of interest and specialization into new and unprecedented patterns of integration.

\section{Technology for added value}

The very concept of technology is undergoing fundamental change or metamorphosis of its own. Originally simple tools, later machines of increasing complexity and multitude of separate parts, yet mostly dedicated to a well defined, usually a single purpose. Such "dedicated" technologies were often interconnected into larger arrangements (like factories), supply and demand chains, fixed or reconfigurable production systems (RPS) or lines. Their technological components were interconnected while retaining their specificity and dedication. Especially, the phenomenon of globalization, in its search for the cheap labor, brought forth worldwide movement toward product components.

New technology is now moving from a simple interconnection to substantial integration and from the widespread final-customer remoteness to the value dictum of producing "as close as possible" to the final customer or consumer (e.g. Speed factories, like Adidas). The traditional maximization of productivity is being superseded by the maximization of added value.

Added-value innovation and invention clearly changes major premises of competition and progress. The shift is form narrow specialized pursuits towards multidisciplinary integration. There is a wealth of ideas and thoughts in all areas, disciplines and specialties. In a traditional scientific approach, these ideas and achievements remain separate, unconnected and seemingly unrelated. Only the very gifted, curious and imaginative among us are starting to see connections between artificial "disciplines" and "unrelated" concepts, nurturing their ability to put it all together and create something entirely new at the intersections of traditionally created specialties and sub-specialties.

A variety of new technologies have now become "components" of more or fully integrated (not merely interconnected), larger, more complex, self-sufficient and self-sustainable "environments", distributed regionally and locally, bringing maximum added value as close as possible to the final consumer or customer.

The closest historical precedents to IPE (Integrated Productive Environment) are so called "Industrial cities" of the pre-war Bata concern in Moravian Zlin. Bata did not produce and export shoes, but "exported" industrial cities (70 of them in the pre-war decade), capable of producing shoes (and other products) as close as possible to their final consumers, all over the 
world. Their added-value model was the very opposite of globalization, and an excellent example of the power of localization on a worldwide scale. Their incredibly successful innovations were cut short by the Nazis and then the Second World War and the unfortunate post-war consequences of communism. Yet, we can still learn from their rich inheritance.

\section{What is added value?}

"Added value" is certainly one of the most used expressions in business and politics, often confused with the "value added" of misplaced taxation efforts. The very concept of added value is often oversimplified by politicians and the media, thus further weakening its powerful role in our post-global relocalization era. Here we take a few paragraphs on added value concepts and definitions, to make sure that the added-value innovation and its IPEs are properly understood and implemented.

During the so called globalization and its distributed process of global sourcing, sections and components of the internal processes were being outsourced to remote external providers and contractors in search of the lowest cost and highest productivity contribution.

However, every operation and every string of operations must be adding value. To serve the global customer means that also the highest possible added value must be identified and exploited. Only then can the firm deliver the best quality at the lowest cost and the greatest speed - the necessary condition for long-term self-sustainable competitive advantage.

The outsourcing phenomenon is the best captured by Stan Shih's "Smiling Curve" (Fig. 3). Both outside ends of the extended process, i.e. R\&D, design and after-sales services are claiming larger and larger portion of the added value, both upstream and downstream of the value chain. The value-added "smile" is getting broader and deeper - pointing to new business opportunities and new outsourcing arrangements. Clearly, operating as far as possible from the final completion process and its customers has backfired. (Paradoxically, this wasteful and misplaced strategy actually helped China in its rapid industrialization later on.) The Bata model was correct, and being as close as possible to the final customer is a new paradigm.

Outsourcing to customer becomes an increasingly effective local strategy, as self-service, do-it-yourself; disintermediation and mass customization bring more and more customers into longer-term relation-

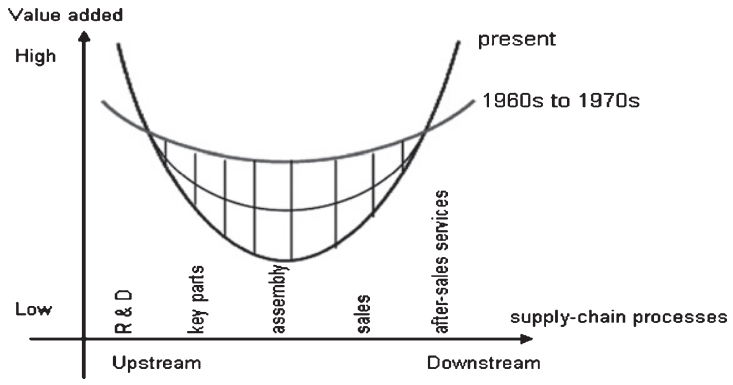

Fig. 3. Stan Shih's "smiling curve".

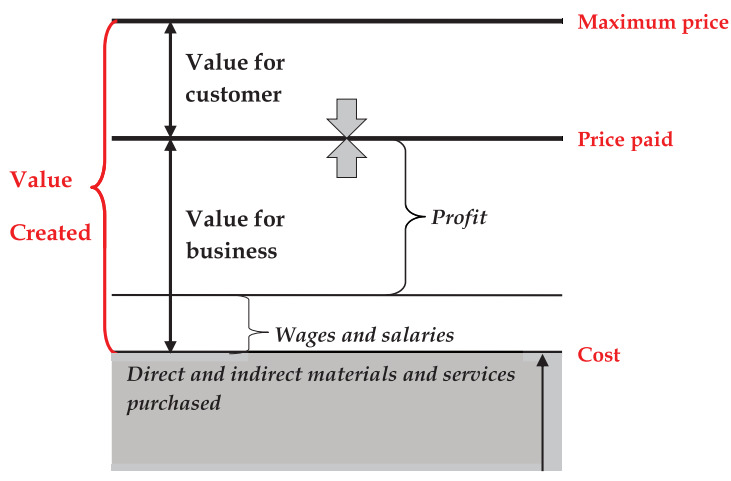

Fig. 4. Definition of the added value.

ships with the producer or provider. More and more of lower added-value activities are being outsourced directly to customers who are becoming much more effective in performing them (e.g., automated teller machines, hypermarkets, self-serve kiosk technology, etc.).

A cooperative network replaces the firm as a unit of competition. Adaptability and flexibility, as well as continuous reshaping and optimization of networks, are becoming more important to corporate success than operational performance. Strategy for agility and marketplace differentiation is more important than cost reduction and execution - effectiveness drives efficiency. It is, at last, more important to do the right things, rather than just doing things right.

In Fig. 4, notice that there are two added values: for the business and for the customer. Both are important and interrelated. From the above definition, it should be clear that the maximum price the customer is willing to pay is crucial. Profit is only a part of the added value, as are wages and salaries. Business optimal strategy is clearly three-fold: price actually paid should be kept relatively stable; push the maximum price up (maximize added value to the customer); and 
reduce cost (to increase the value for business). Thus customer and business are bonded in a long-term trust and cooperation. The traditional fiddling with the price paid (as in a Turkish bazaar) is finally waning. Business and its customers are integrated into a functional whole of trust and cooperation.

\section{Closing notes on integrated productive environment}

Both the components and final products have to be integrated into larger and more complex products of maximum added value. Like in an automobile (or human community), all such components must function seamlessly and flawlessly together. So there is a new technology of integration, i.e. pulling the components together into a higher functional whole. Such higher-complexity product itself becomes a component at a next level integrated system, which is also a higher-value form of technology. Such highest-level complexes we have referred to as Integrated Productive Environments (IPEs).

Typical example of the highest IPE would be a complete town: productive, flexible, modular, fully equipped to provide food, products and services, including housing, education, health care, sports and entertainment, all in the closest proximity to regional or local customers. (see the so called "Industrial cities", exported globally by the Bata Corporation in the 1930s.)

The ways such IPEs are designed, put together, operated and used, represent the new, innovative ZETFoundation focus. It is clear that such orientation requires competent cooperation of many individuals, companies and institutions, at multilayered cultural, professional and knowledge levels. It is this kind of deep cooperation that is much needed in restoring regional and local equilibrium. We call them Condensation nuclei around which the spontaneous and self-sustainable human activities can naturally evolve.

Such IPEs are also needed in education, selfgovernment, healthcare, defense and environmental protection. One of the largest threats to our world is non-cooperation, political party solidarity, and populist isolationism (like the "America First!" strategy). Any such separation, withdrawal and isolation breed similar responses and chain reactions all over the global society. The solution is found in evolving local and regional IPEs worldwide, establishing their cooperative patterns in trading their technology, knowledge and experience. Clearly, the intercultural experience is needed for acquiring the understanding and knowledge of IPEs.

\section{A summary of the Bata System}

Most of the ideas introduced, represent a going concern of the ZET-Foundation. The search for restoring regional and local equilibriums, using the concepts of Integrated Productive Environments, are inspired by the rich traditions and heritage of the Industrial cities (at least 70, most of them still functional, were "exported" all over the world, just during the 30 s of the $20^{\text {th }}$ Century) by the Bata company of Zlin, Moravia.

A short overview of the Bata management system concludes our statement:

The Bata Management System (BMS): Bata's enterprise was organized and behaving as a living organism - learning, adapting and self-organizing. It was also viewed as such by Tomas and Jan Bata and their associates - a label for Bata employees. They felt to be parts and components of a living organism, not of some well-oiled, well-crafted machinery. The company was a privately held corporation, not a publicly owned one: there was no public stock and no public trading with company ownership. The company created a harmonious human, ecological and architectural co-existence with its immediate environs of Zlin and the Moravian region as a whole. Employees were partners and associates (co-workers), capable of effective cooperation, sharing and considerable sacrifice. Bata Co. practiced the system of Ten Principles, i.e. key dimensions and their practical realizations, which formed the Bata Management System (BMS) (Table 1):

Table 1

The ten leading principles of bata

\begin{tabular}{lll}
\hline & Dimension & Realization \\
\hline 1 & world class & global benchmarking \\
2 & cooperation & partnerships and alliances \\
3 & self-government & private corporation \\
4 & participation & profit sharing \\
5 & co-ownership & employee capitalization \\
6 & self-management & shop autonomy, internal markets \\
7 & co-entrepreneurship & customer, internal and external \\
8 & competition & internal benchmarking \\
9 & service to the public & purpose of business \\
10 & synergy & balanced system of all dimensions \\
\hline
\end{tabular}


About the author

OVERVIEW: https://en.wikipedia.org/wiki/Mil an Zeleny

PUBLISHING ACTIVITY: http://www.milanzel eny.com/en-US/pages/1/-/6/23/publishing-activity
Selected bibliography

We are undergoing a major transformation, not just a crisis: https://www.financialsense.com/contribut ors/milan-zeleny/transformation-not-crisis-glob al-economy

Transformation in economics:

https://en.wikipedia.org/wiki/Transformation_ in_economics 